\section{A LINGUISTIC LANDSCAPE STUDY OF ADVERTISING SIGNAGE ON SKYTRAIN}

\author{
Kritnucha Sutthinaraphan ${ }^{1}$
}

\begin{abstract}
The aim of this study is to examine to what extent and in what ways Thai and other languages, especially English, are used in the rapid transit system in Thailand and to describe the bilingual strategies used. The data were collected through photographs of advertising signage in the BTS ${ }^{2}$ Skytrain system and open-ended interviews. Three stations, Mochit, Payathai and Siam, were selected to be analyzed. The results revealed that the majority of the signs (65\%) are in bilingual Thai and English by script. On the whole, the Thai language is used for informational purpose, while English is used for symbolic function to express senses of luxury, technological advancement and internationalism. It is found that there are many types of code-mixing, the combination of English and Thai script, lexicon, syntax and phonology. To supplement the quantitative data, key players (i.e., advertising employees) were interviewed, who stated that the reasons for inclusion of English language in advertising are stylishness and flamboyance.
\end{abstract}

\footnotetext{
1 Special instructor at Chulalongkorn University and several private language institutes. He completed his Master's Degree in English as an International Language at Chulalongkorn University and Bachelor's Degree in Business English Communication at Thammasat University. 2 BTS means Bangkok (Mass) Transit System
}

\section{Introduction}

The study of linguistic landscape has become an increasingly important approach to understanding multilingualism in its social context. It refers to the study of public signage (Spolsky, 2009). This includes linguistic objects such as street signs, commercial signs, billboards, public notices, etc. (Ben-Rafael et al., 2006, as cited in Huebner, 2009). Backhaus defines a sign as "any piece of written text within a spatially definable frame".

Linguistic landscape studies have regularly shown the important role that English plays as an international language in the world today (e.g. Blommaert, 2013; Jaworski \& Thurlow, 2011; Shohamy, Ben-Rafael \& Barni, 2010). In an era of globalization, distant parts of the world become interconnected and English has become the lingua franca used to communicate with people of dissimilar backgrounds. This fact is reflected in virtually all studies of linguistic landscapes world-wide. At the same time, the preponderance of English in the public sphere can also be a reflection of power relations and notions of identity. Two domains where English is particularly present in the physical environment are advertising and public transportation. The current study combines both of these domains in its investigation into the linguistic landscape of advertisements on the BTS Skytrain in Bangkok.

Inaugurated in 1999, the BTS Skytrain was the first electric mass transit railway system in Thailand. The BTS system is located in the urban areas along the heart of Bangkok. Each train can serve up to 1,000 passengers per journey. It operates in two main lines, Sukumwit and Silom, with a total number of 34 stations as 
shown in Figure 1 (BTS, 2015). The BTS Skytrain is a mode of transportation for the middle-class and residents who live along the railway trajectory. Tourists travelling in urban area also ride the BTS as it is convenient and inexpensive.

BTS ridership is usually heavy to the extent that it is difficult to find a seat. During early morning and evening rush hours and on weekends, the trains are literally packed. As such, they are ideal locales for advertising to a captive audience. The linguistic landscape of a BTS station will typically include official regulatory signs, informative or instructional signs on machines such at ATMs and ticket dispensers, and advertisements in many forms. Large billboards grace the stairwells and platforms. Long, narrow vertical banners are attached to the platform pillars; Ads can also be found on the train cars themselves, the exteriors of which are often painted to promote a product or service. Inside, posters occupy any free space on or next to the doors and loom over the heads of passengers, whether seated or standing. This pervasiveness of advertising together and the composition of the ridership make the BTS a good site for the investigation of a linguistic landscape.

A number of studies have examined linguistic landscape in Asia. Kasanga (2012) conducted a linguistic landscape study of a commercial neighborhood in central Phnom Penh, Cambodia. The data derived from storefronts and a few billboards in that area. The distributional pattern showed that Khmer, the official language of Cambodia, is the most prominent language while English ranked second in the signs observed. However, the majority of the signs are bilingual
Khmer-English at 51 percent. The author indicated that this may be due to gentrification and an educational policy that has enabled English to become more popular.

Recently, Manan, David, Dumanig and Naqeebullah (2015) pointed out the linguistic landscape of Kuala Lumper in Malaysia. Government and private signs were gathered from five neighborhoods: Little India, Bukit Bintang, Bank Nagara, Musjid Jamek, and China Town and Kota Raya (adjacent communities). Photographs and interviews are the two major sources of data collected in their study. The results showed that Bahasa Malayu, the national language, is by law the compulsory language in every sign. From a more pragmatic economic position, the use of English in advertising is widely used to express the symbolic roles of conveying notions of internationalization, westernization, modernity, success and attractiveness. Further, the use of foreign languages, Chinese and Indian, are prominent in specific communities to express their ethnolinguistic identities.

Some studies have focused in part or exclusively at the linguistic landscapes of public transportation systems. In 2006, Backhaus conducted an empirical investigation into multilingual signage in Tokyo. Both official and non-official signs were photographed along 28 stations of the Yamanote Line. The results showed that official signs contained expressions of power associated with the national language, Japanese. English, Chinese and Korean were used to communicate solidarity with non-Japanese riders. For instance, the Korean language appeared in the Korean community, and English performed a symbolic function of internationalism. 


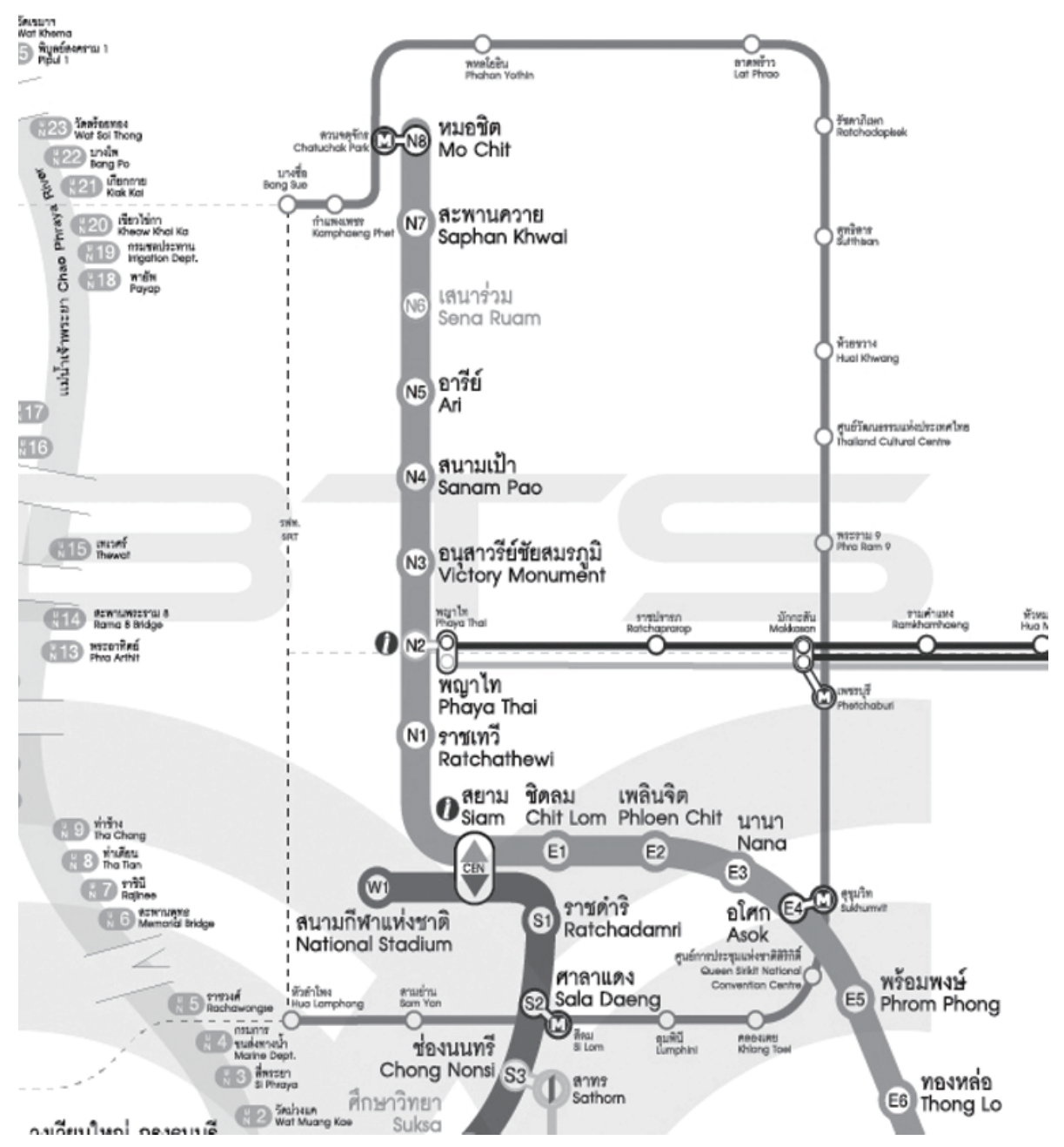

Figure 1: BTS Route Map

Lock (2003) pointed out the use of language on advertisements on the Hong Kong Mass Transit Railway. The data comprised 75 advertisements from the MTR trains and on platforms from Fortress Hill station to Kowloon Tong station. The findings revealed that English was utilized to manifest consumerism and internationalism. Cantonese, the local language, was used to localize international products, especially food and drink, while Mandarin Chinese was deployed to exhibit traditional culture and Chineseness, for example Chinese New Year.

In Thailand, Huebner (2006) investigated environmental print of 15 neighborhoods in Bangkok, Thailand. He compared the signs in various communities as well as 
the Skytrain. Six hundred and thirteen signs were analyzed according to codemixing and language dominance perspectives. The findings suggested a classification of neighborhoods into five categories or types: those neighborhoods with predominantly Thai monolingual signs, those with a balanced of Thai monolingual signs and Thai-English bilingual signs, those with predominantly Thai-Chinese multilingual signs, those with predominantly Thai-English bilingual signs, and finally those neighborhoods with a preponderance of multilingual signs in other languages. Huebner placed the Skytrain as a 'neighborhood with a preponderance of Thai-English bilingual signs. Ultimately it was assumed that the signs were aimed at both local and foreign riders. The current study differs from the Huebner study in that it focuses solely on the linguistic landscape of the BTS and is further limited to advertisements, excluding regulatory and informational signs. Furthermore it adds a qualitative dimension missing in Huebner 2006.

\section{Research Questions}

1. To what extent is the advertising on BTS monolingual or multilingual?

2. Which languages other than Thai are represented in advertisements on Skytrain?

3. What patterns of language arrangement is employed in the advertisements?

4. What kinds of code-mixing and hybrid language are found in advertising?

5. Why do the creators of such ads decide to use English?

\section{Methodology}

\section{Data Collection}

Three BTS stations were selected to be investigated: Mochit, Payathai and Siam. They were chosen for analysis because they are popular stations for Thais, expatriate residents and foreign tourists as they are all interchange stations. They are located along the Sukhumvit line. Mochit is an interchange station with the MRT subway and located near the famous Chatuchak weekend market. Payathai station is an interchanged with the Airport Rail Link. At the Siam station, the Sukhumvit line intersects with the BTS Silom line, and is connected to several prestigious shopping malls.

One hundred and seven photographs were taken by iPhone 6 camera from $6^{\text {th }}$ October to $3^{\text {rd }}$ November 2015. The data consisted of advertisements in the stations and on the train. They included advertising posters, billboards and banners on the stairs, on the ticket floor, on platforms and mounted on pillars, as well as within the trains themselves.

After analyzing preliminary data, interviews were conducted with two informants from the advertising industry to provide greater depth of understanding of the motivations behind the language choices in the ads. During the interviews, the voice recorder application on iPhone 6 was also used.

The two informants were questioned about language in advertising and the reasons why English is so prevalent. The first informant, Kwan, is a copy writer at a Japanese advertising agency in Thailand. Her responsibility is to create the content of the advertisement. She has produced 
several advertisements for magazines, newspapers and the BTS Skytrain. The second informant, Nat, is a marketing consultant at a German advertising agency. He has been involved in many advertising campaigns for Thai and multinational brands.

\section{Data Analysis}

The data were analyzed by using descriptive statistics for quantitative analysis. Percentages were calculated to find distribution of the signs. Reh's taxonomy (2004), Toolan's components of commercial print advertisements (1988) and Huebner's code-mixing framework (2009) were employed for qualitative analysis.

\section{Results and Discussion}

\section{Distribution of Multilingual Advertising Signage}

With regard to the first research question, concerning the extent to which the advertising on the BTS is monolingual or multilingual, Figure 2 shows that the majority of advertising signage on the BTS is bilingual. As to the second research question, regarding the languages represented, only English and Thai were found. Sixty-five percent of the signs were bilingual in English and Thai, followed by monolingual English signs at 22 percent. In only 13 percent of signs was the entire text written in Thai script. Surprisingly, no other language was found. The texts, whether bilingual or monolingual, together with the visual images perform both an informational function to convey a message and a symbolic function to express an identity or evoke an emotion. For example, in an ad for Brand's, a dietary supplement (see Picture 1), written entirely in Thai and presumably for a Thai readership, the message translates as "Prepare to pursue your dream. Drink Brand's every day." But first, the viewer's attention is drawn to the gaze of Mr. Kiatisuk "Zico" Senamuang, a coach for the Thai national football team and an icon of Thai athletic pride. He's looking directly at the viewer and is holding a bottle of Brand's. The combination of the celebrity directly addressing the viewer/reader both visually and verbally, together with the written promise of good things to come, trigger an emotional response and a sense of "Thai-ness" that we share with "Zico" and with Brand's, while indicating it is daily dietary supplement.

Similarly, monolingual English signs are used both to convey information and for the symbolic function of expressing sophistication of a brand image. Monolingual signs in English mostly appeared in advertisements related to metropolitan condominiums, technology products and travel businesses. They tended to have a sense of luxury, advanced development, technology and internationalism. The target audiences of these products are both expatriate residents and high-income Thai riders who are literate in English. Picture 2 represents monolingual English advertisement of Turkish Airlines. Ostensibly it informs the reader about the size of its lounge in Istanbul. But together with the wide-angle image, it symbolically positions the airline as a world class enterprise capable of offering its international passengers a level of service and luxury second to none. 


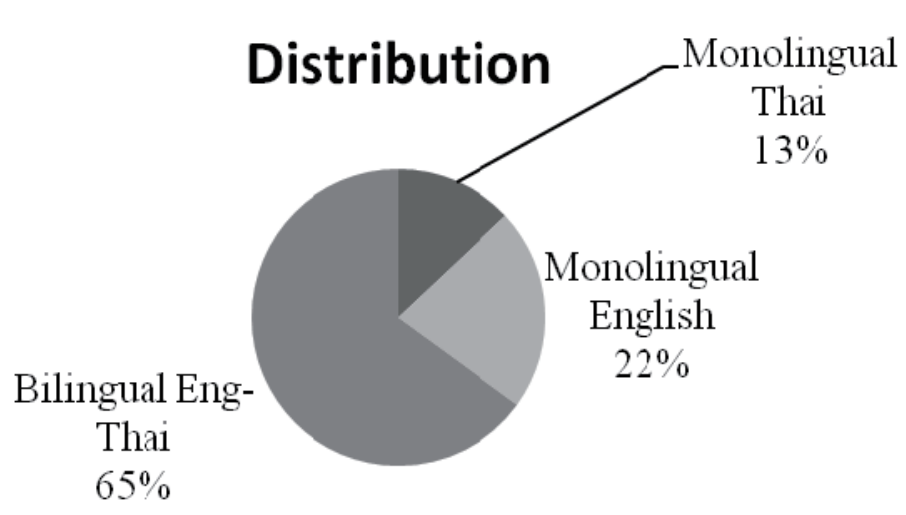

Figure 2: Distribution of Monolingual and Bilingual Signs

\section{The Display and Arrangement of Information}

While the ads in Pictures 1 and 2 differ in their choice of language, image and amount of text, they both organize text to present their message effectively. To do this, advertisements typically employ a sequence of acts, or act sequences, akin to Olshtain and Cohen's (1983) speech act sets or moves as in Swales' (1990; Swales and Feak 2012) move analysis of academic writing. For example, in their cross-linguistic analysis of U.S., Japanese, Chinese and Korean TV ads, Schmidt et al. (1996) found that TV commercials from all four cultures employed headlines and supporting moves. With regard to print media, Toolan (1988) identified typical components (or act sequences) of commercial advertisements as including a headline that draws the audience's attention, body copy which contains the details and information about the products, signature line bearing the brand name, followed by a slogan and standing details (i.e., contact information) at the bottom of the advertisement (as cited in Huebner, 2009). The act sequences of a given advertisement may vary from this prototype depending on its subject matter, purpose and intended audience.

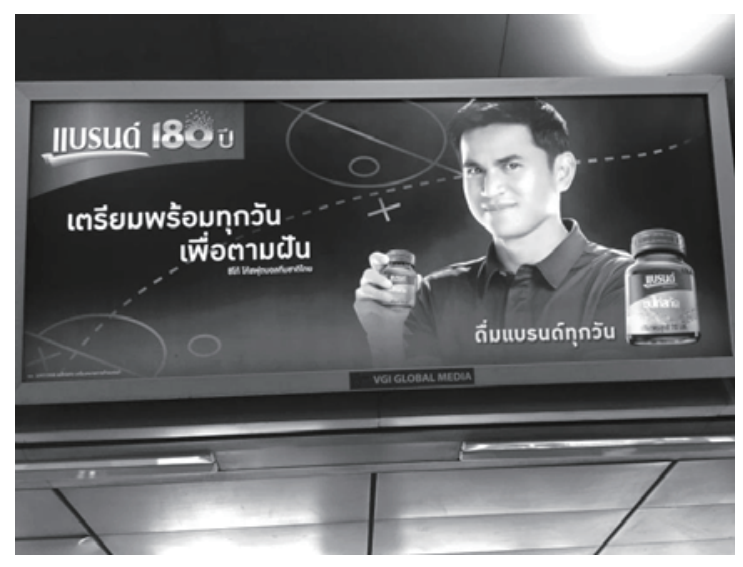

Picture 1: Drink Brand's Every Day

Not surprisingly, since Toolan's model was proposed for print advertisements in newspapers and magazines, the BTS advertisements investigated here rarely contained all five components. Nevertheless, since newspaper print ads and public commercial signage share similar goals, the framework of act sequences described by Toolan can apply to the advertising found on the BTS. A few posters contained all of the components. For instance, Bangkok 
Bank's ad in Picture 3 contains all of the above components. It is located on an

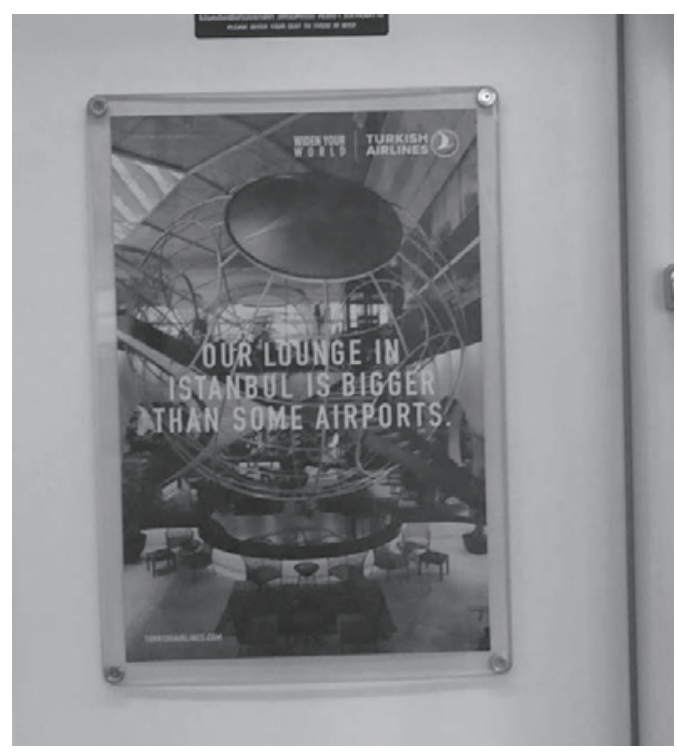

Picture 2: Turkish Airline Lounge

interior wall of a train car, where passengers standing have time to read the text, the purpose of which is to provide detailed information about this financial product. Similarly, passengers have time to read advertisements above the passenger seats, which contain headline, body copy and signature line. However, most ads were found to constitute only headline, signature line, and slogan without body copy and standing details. A presumption of this outcome is that for advertisements placed on the stairs, platforms and ticket floor where passengers are in transition, riders may not have time to read a lot of information in the body copy, and contact information in standing details is unnecessary due to the widespread availability of the product. Vertical signs attached to the pillars on the platform contain even less writing, constrained as they are by their shape and limited space for print. These signs usually mention only headline, signature line and slogan. Because they advertise well-known consumer goods, such as Pepsi Cola, their aim is to raise brand awareness. So while the Toolan componential analysis of moves or act sequences for print ads can provide a framework for the analysis of commercial ads in public spaces, the extent to which that model is adhered to is a function of the sign's physical shape and size, the viewer's physical and temporal relationship to the ad, and the viewer's assumed background knowledge and experience.

With respect to language use in multilingual signs, Bhatia (1987) found a clear division of labor in commercial signs in India. Headlines tended to be in English, Sanskrit or Persian. The body copy and signature line were most often in Hindi. But the product name was usually in English. While in the current study only two languages were observed, in the majority of cases the product name and often the signature line were in English while the rest of the ad frequently employed Thai. Thus the use of English puts the corporate name "out there" for all to become familiar with while adding an air of cosmopolitan sophistication to the product or service being offered, while Thai is used to convey the vital information. 


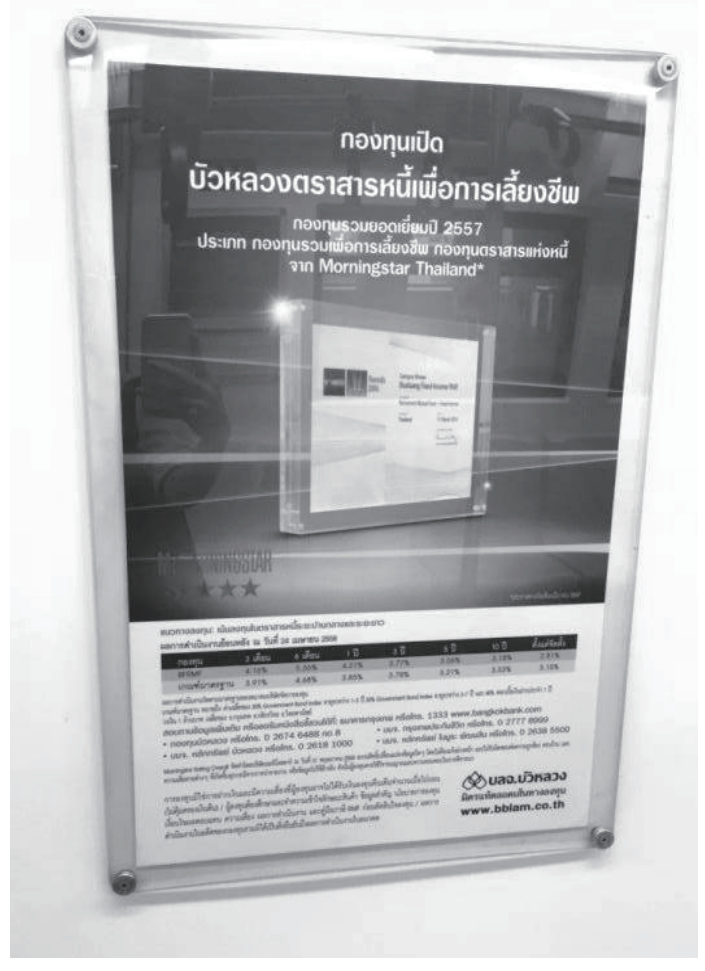

Picture 3: Bangkok Bank

This type of ad, in which only the product name and perhaps the signature line are in one language while the rest of the ad is in another, contains what Reh (2004) has labeled a complementary arrangement of bilingual information. In this type of arrangement, the content in one language is completely different from the content in the other. An example can be seen in Picture 4, where only the brand name "AIS Fibre Broadband" and the phrase "Watch Spiderman 2 now" are in English. The Thai text promotes the qualities of AIS Fibre Broadband, "Faster and more fun" and "high speed."

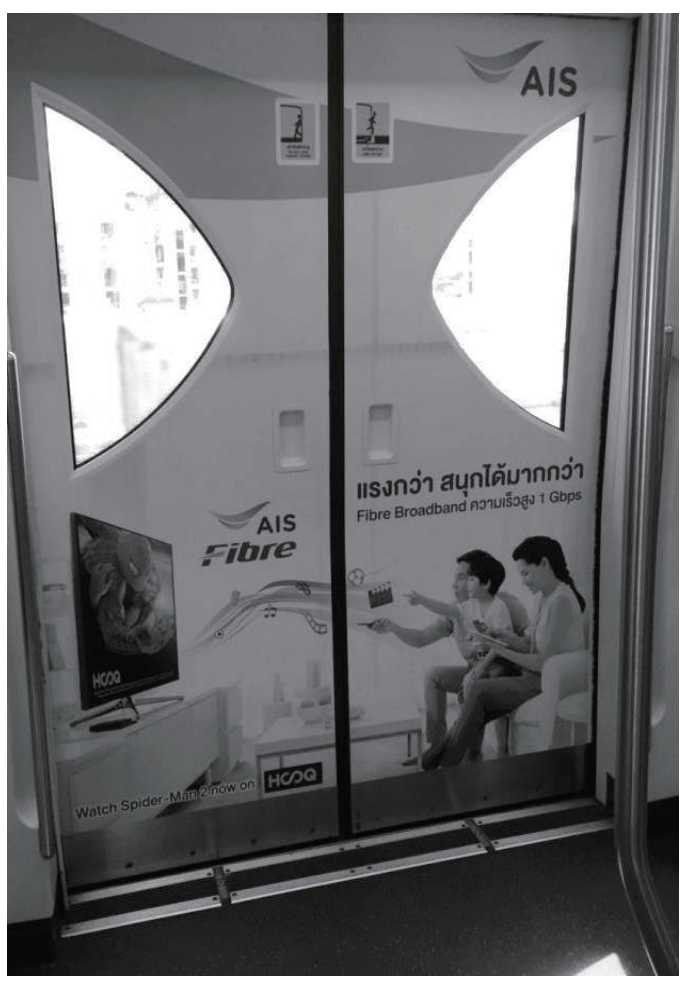

Picture 4: AIS Fibre

Other possible patterns of information distribution across language in bilingual signs as postulated by Reh are fragmentary, overlapping and duplicating. In signs displaying a fragmentary arrangement of bilingual information some but not all of the content which appears one language also appears in the other. The ad in Picture 5 is an example of a fragmentary arrangement of information. It was an advertisement from $C P$, a processed food company. The headline reads "New Ready Meal CP Balance" in Thai. Most of the text is written in Thai except the words "Ready Meal." This is the English equivalent of the Thai headline "Arharn phrom than." The rest of the message of the ad is in Thai only. The Pantene hair product ad (Picture 6) represents an overlapping arrangement, in which the totality of the message 
presented in two languages, each of which contains information not contained in the other, but some piece of the information is repeated in both languages. Here the content is presented in English and Thai. The phrase "new Pantene 3 minute miracle" is in English. The Thai text can be translated as "repair 3-month damaged hair...." The two languages convey different information except one word "new" that appears in both languages. Together the two languages convey what the product does ('3-month hair repair") and how it does it (a "3-minute miracle").

Duplicating signs contain identical information in two languages. They are intended for the widest audience, including those who may be monolingualmonoliterate speakers / readers of one language or the other. Lock in his 2003 study of the linguistic landscape of the Hong Kong subway system reported that while commercial signs were more likely to display fragmentary, overlapping or complementary arrangements of information, duplicating arrangement was found predominantly in official signs. Since the current study was limited to commercial signs and no duplicating arrangements were found among the data, it might be proposed that duplicating arrangements of information is a universal tendency of official bilingual signs, whose primary function is to inform or regulate.

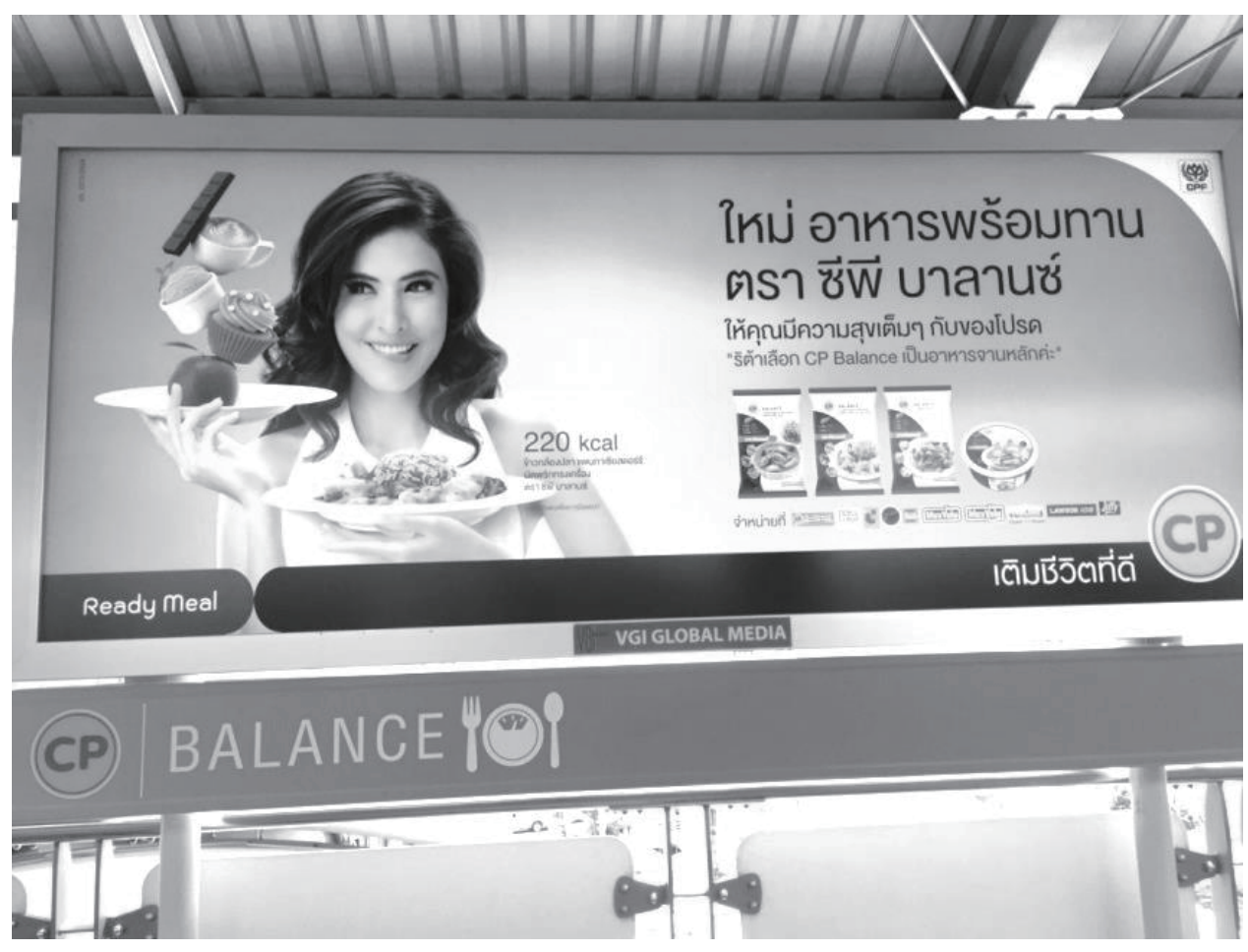

Picture 5: CP Ready Meal 


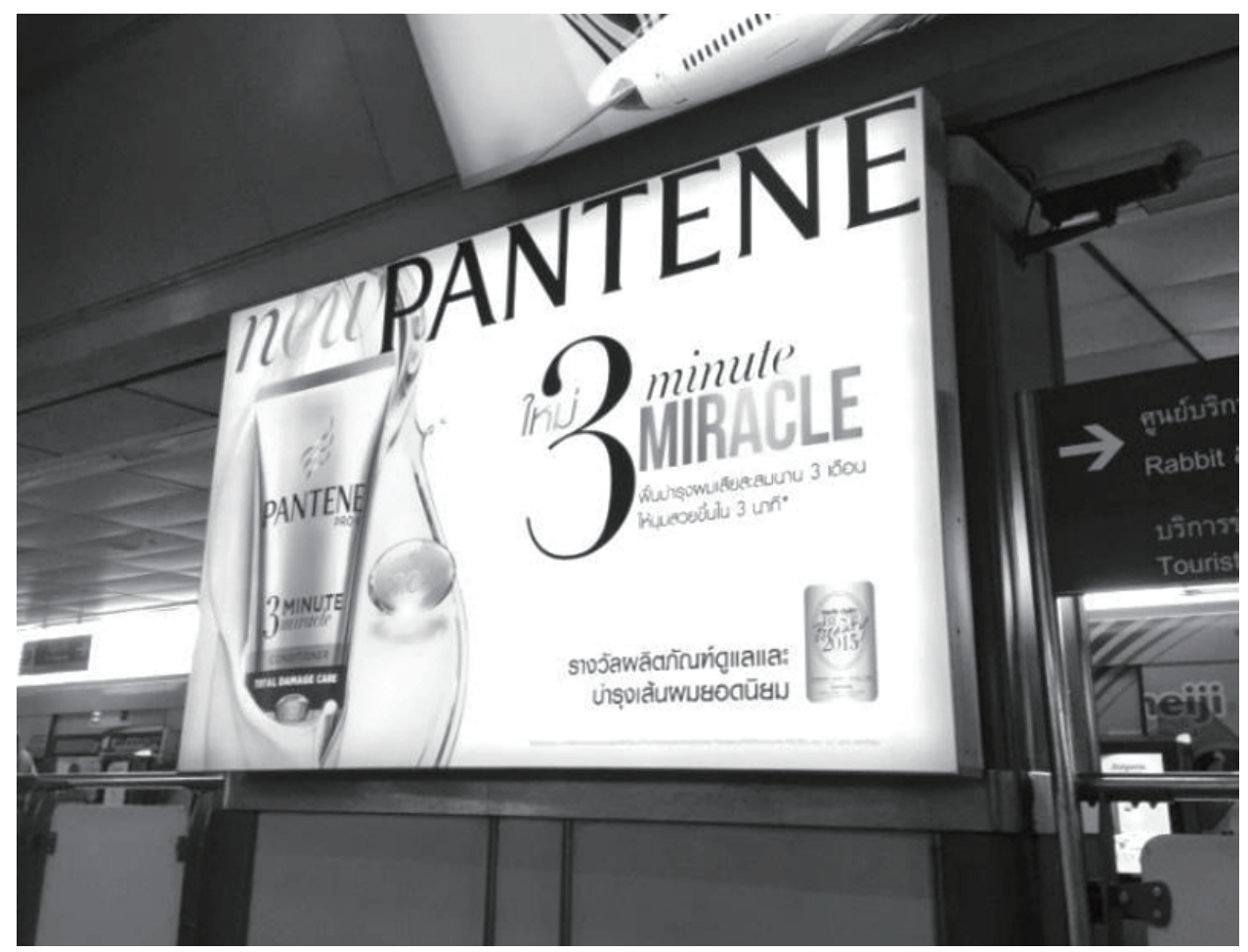

Picture 6: Pantene 3-Minute Miracle

\section{Code-Mixing, Borrowing and Hybridization of Language}

While the bilingual organization of information across act sets provides clues to the purpose and intended audience of an ad, it does not account for the complex linguistic consequences of the language contact it describes, specifically borrowing and code-switching. Borrowing has been defined as "The introduction of a word (or some other linguistic feature) from one language or dialect into another." (Crystal 1992: 46). Crystal refers to the products of lexical borrowing as "loan words." "Loan blends" are lexical items whose original meaning is borrowed but only part of the form. "Loan shifts" occur when the meaning is borrowed but the form is nativized (Crystal 1992: 4647). Code switching or code mixing, by contrast, involves the shift from one language to another in a single utterance or conversation.

With regard to BTS ads, the majority of complementary, overlapping and fragmentary ads in the data involve either lexical borrowing or code-switching. For example, in the fragmentary arrangement of information in Picture 7, the Thai portion contains the borrowed word เคลีย in the phrase เคลียลึกทุกสิ่งสกปรก. In its commonly spoken form, the word pronounced as [klia] has adapted to Thai phonological rules. The phrase เคลียลึกทุกสิ่งสกปรก translates literally as "clear deeply everything dirty." In both Thai and the English text "Clear, 
Nothing to hide," the word "เคลีย / clear" functions as an adjective describing a condition "without blemish." But it also functions as a verb meaning "to make clear." or "to remove." Finally, as the name of the product, it also functions as a noun. Not only does the Thai message contain a form borrowed from English, it borrows all of the grammatical functions of the word in English. The ad captures both all of the meanings and all of the functions of the word in each language in parallel but complementary phrases.

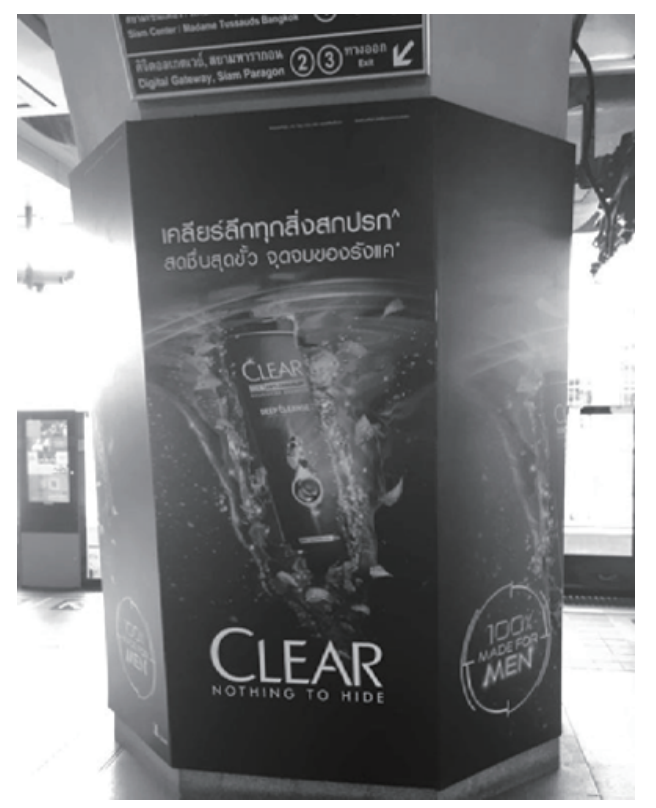

Picture 7: Clear, Nothing to Hide

Another example of lexical borrowing is in an Epson printer ad (Picture 8) that reads "พริ้นเตอร์แทงค์แท้ที่ขายดีที่สุดในเอเชียตะวันออกเฉียง ใต้." meaning the best selling genuine printer tank in Southeast Asia. The word "พริ้นตอร์" has been appropriated into Thai with the same referential meaning and syntactic function as its source word "printer", but written in Thai script, used in a Thai syntactic construction, and when spoken, said with Thai phonology. But it also has the same meaning and syntactic function of an existing word in Thai, namely "kruang pim". It appears that the loan word is replacing a Thai lexical equivalent that is perceived as becoming obsolete in everyday use.

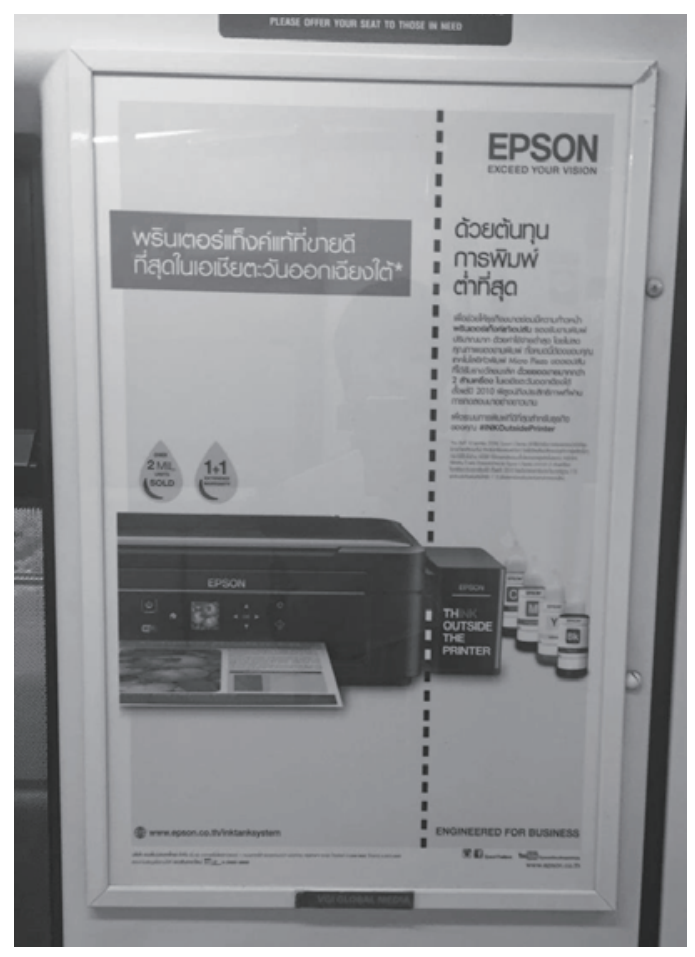

Picture 8: Epson Printer

Adaption of form often entails more than phonology. The sign in Picture 9 contains an example of clipping or what Crystal (1992) would call a "loan blend." The first phrase on that sign reads "ปลายปี" (plai pii), translated as "end of year"; the second phrase, "โปรแรง" (pro rang) means "hot / heavy promotion." The word "โปร" ("pro") in the second phrase is borrowed from the English "promotion" with the meaning of "the act of promoting" or in retail talk, a sale. The loan word has adapted to Thai morphologically through clipping and phonologically with an unaspirated /p/ to the extent that the origin of the word is 
unrecognizable to the non-Thai ear. It seems that as in the source language, the Thai word functions as a noun.

Another consequence of language contact is the use of English acronyms in Thai texts. For example, the acronym "SMS" is an English acronym which stands for Short Message Service (see Picture 10). Unlike the case of "clear" which has been incorporated orthographically, it is written in English script embedded in Thai text. As such, it might be considered an instance of intrasentential code switching. Theoretically, it is a noun as an example from Krung Thai Bank translated as "Always feel safe with SMS." Still, the acronym is used in daily conversations

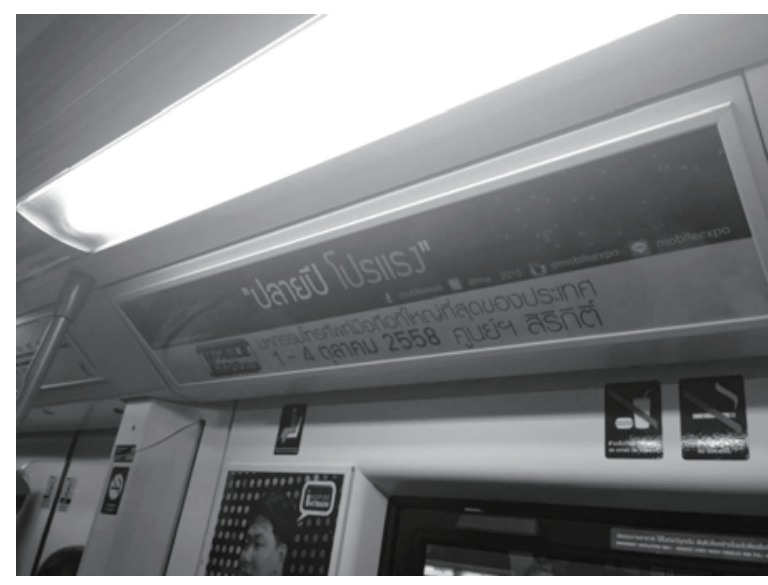

among those familiar with texting, when Thais tend to convert it from noun to verb such as "I will SMS you." Another example of an English acronym written with English script and used with Thai syntax is the retirement fund ad on the interior door of a BTS car (Picture 11). Here, LTF is an abbreviation of LongTerm Equity Fund while RMF refers to Retirement Mutual Fund. Both are nouns and technical terms in the field of finance, accessible to a select subgroup of riders. When translated into English, the sign could be rendered as "invest LTF RMF" without a preposition, a kind of register reserved for those proficient in the language of investment options.

Picture 9: Promotion

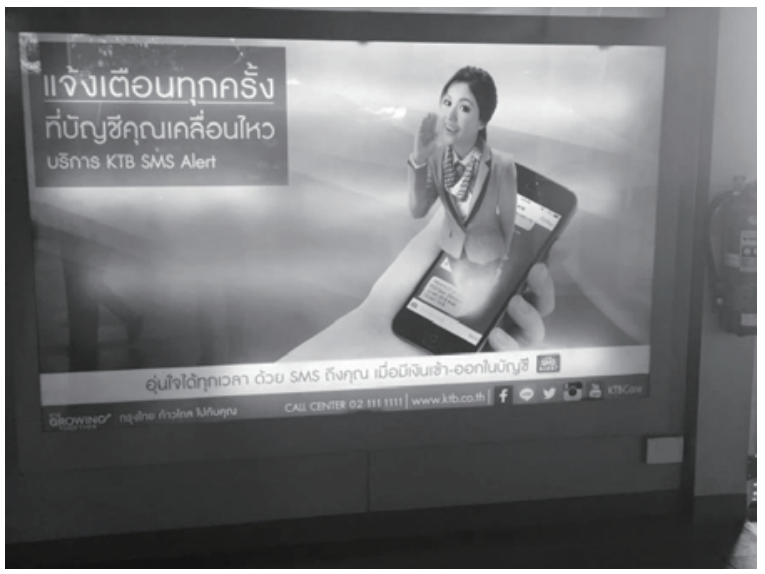




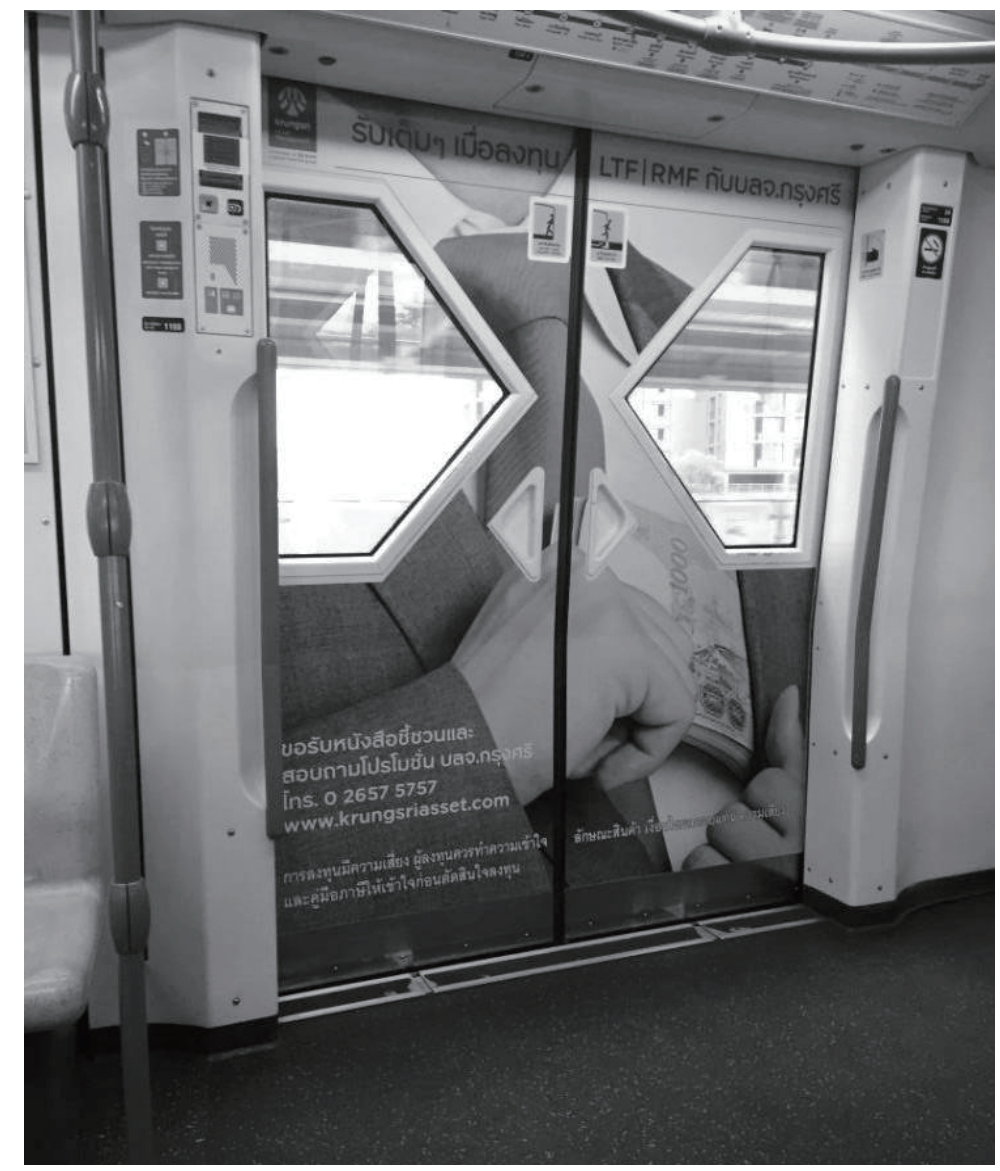

Picture 11: LTF RMF

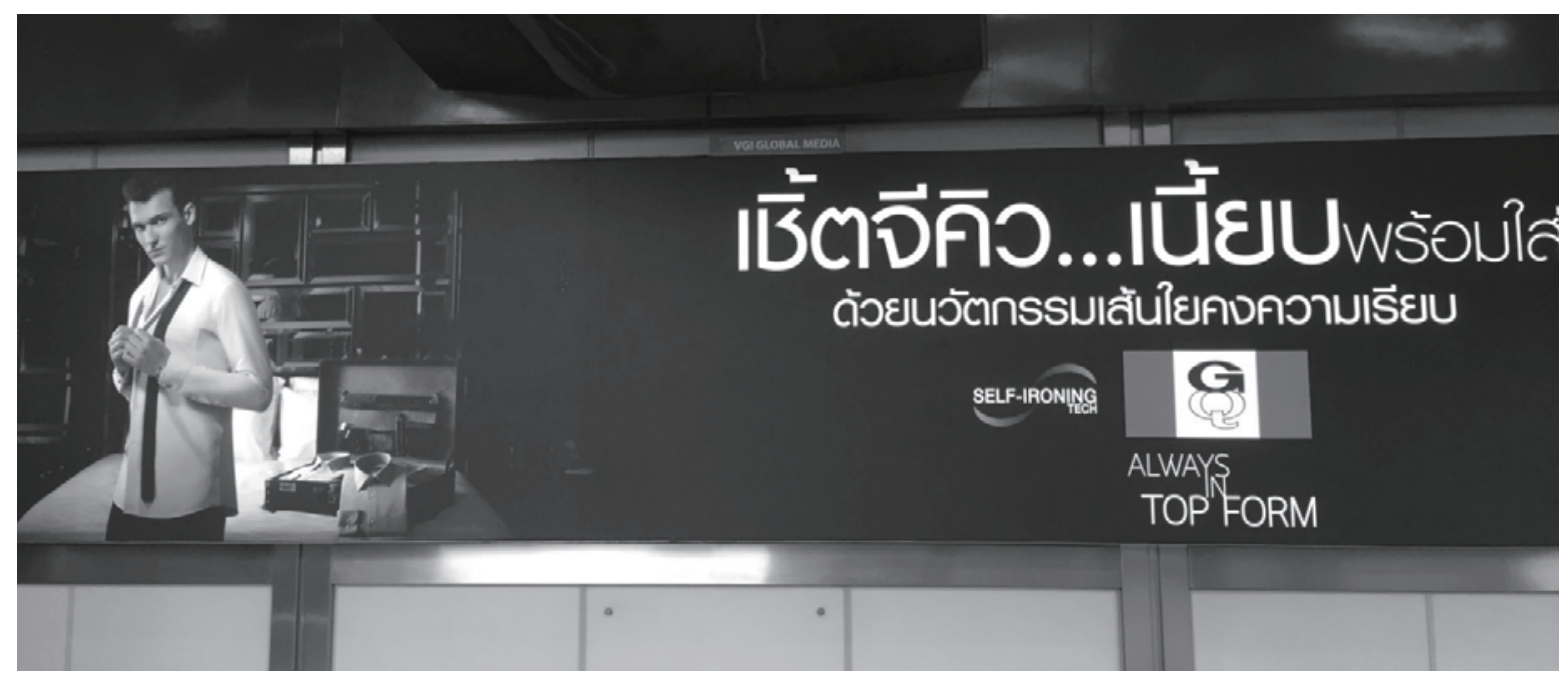

Picture 12: Shirt GQ 


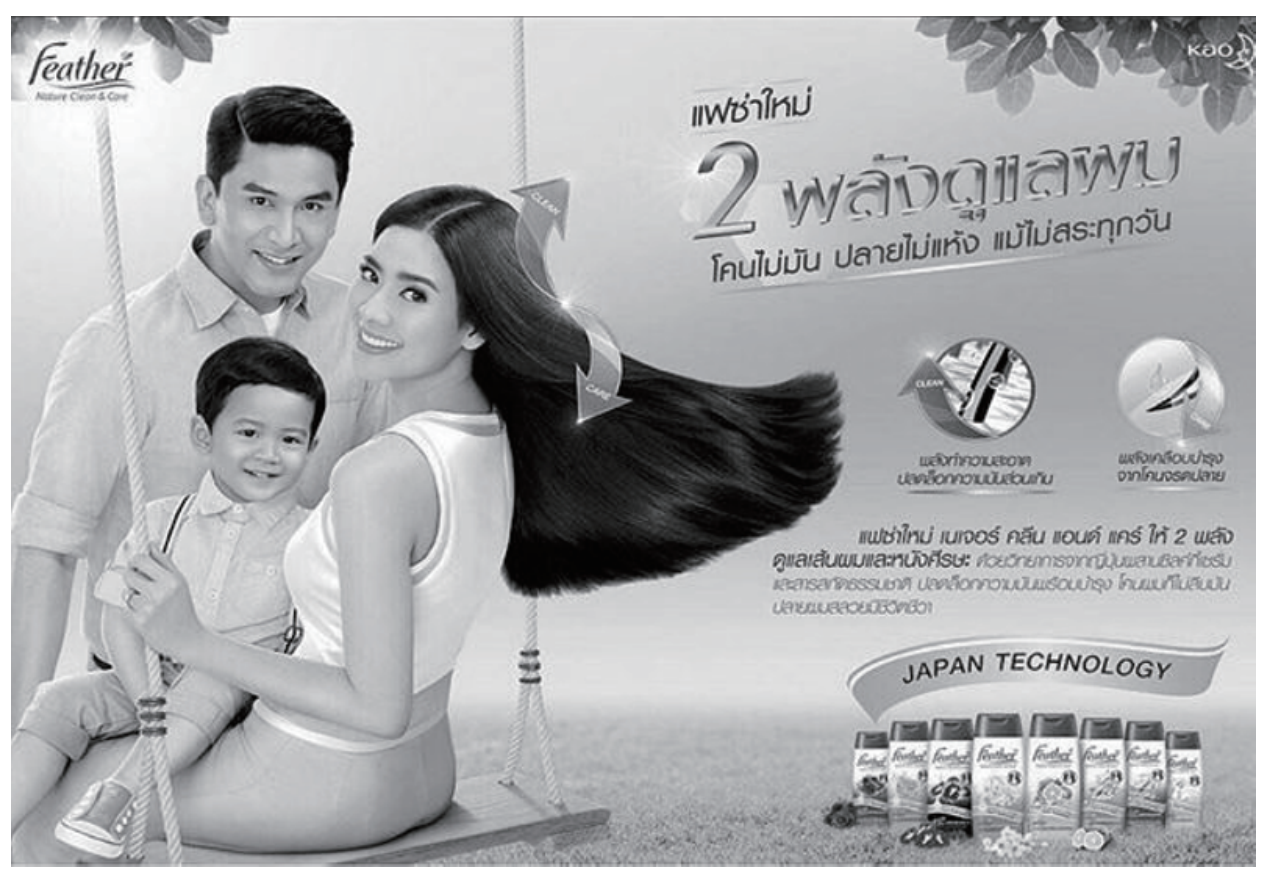

Picture 13: Feather Shampoo

Finally, BTS ads display the kind of hybrid language described in Huebner 2009, with Thai orthography and syntax but English lexicon. In the apparel ad in Picture 12, the phrase "shirt GQ" is in Thai script with Thai syntax as the head noun comes before modifier. However, the ad retains the English word "shirt" and the English acronym GQ from the men's fashion magazine $G Q$ (Gentelmen's Quarterly). In Thai there is a generic term for a garment covering the upper body, "sua." In formal language, people use it as a compound noun with the loan word as in "sua shirt", literally "shirt shirt" in English, to distinguish it from other forms of sua, such as sua tee, sua klam, or sua polo.

The findings show that most advertisements are bilingual in Thai and English. The bilingual ads exhibit fragmentary, overlapping or complementary arrangements of bilingual information. Product names and signature lines tend to be in English; body copy is usually in Thai. The presence of English is pervasive in the form of lexical borrowings, code switching and hybrid structures. The pervasiveness of English in the ads and the ways it is used suggest that the intended primary readership are middle class Thais who have at least some modicum of English proficiency. A secondary audience are expatriate residents and tourists who don't read Thai but who are able to read product name and signature line, thus keeping the product in the readers consciousness.

\section{Why Advertisers Use English: A Qualitative Perspective}

In order to better understand the motivation behind the pervasive use of English in the BTS ads, I interviewed two advertising professionals familiar with ad campaigns on the Skytrain system. Kwan, 
a copy writer, works in a Japanese advertising agency. Her responsibility is creating a message that will appear in the advertisement. She has produced many advertisements which have been publicized in the BTS Skytrain system, for products such as shampoo and air conditioners. She showed me a shampoo brand named Feather. This advertising poster contains several English words (shown in Picture 13). The brand name "Feather" is pronounced [fæ-sa], perhaps from the Japanese. The vowel sounds of both syllables are changed, as well as the consonant in the second syllable, from an interdental fricative to an alveolar fricative. The phrase "Nature Clean and Care" is a Thai transliteration of the English words. . Kwan indicated that when the message is in English, it can create more impact on customers. Moreover, English is an international language which enhances a brand's international image, even when the
English terms are transliterated in Thai script. If they are translated into Thai, she thinks that it would look strange and cheap. According to her, English words are preferred because they are "shorter and memorable."

In the same ad, the words "silky serum" are trasnsliterated in Thai script. Kwan explained further that the target of this product is Thai lower- and middle class people who cannot read English script but who once noticing these English words, will perceive the product as of good quality without necessarily knowing the real meaning of the words. However, we can see English script "Japan Technology" in the body of the ad. Kwan suggested that this is because, according to her clients, if written in Thai, it would look unpleasant. Asked about how to organize the logo in the ad, she indicated that it can be put in any corner of the frame but there must be white background to make it prominent.

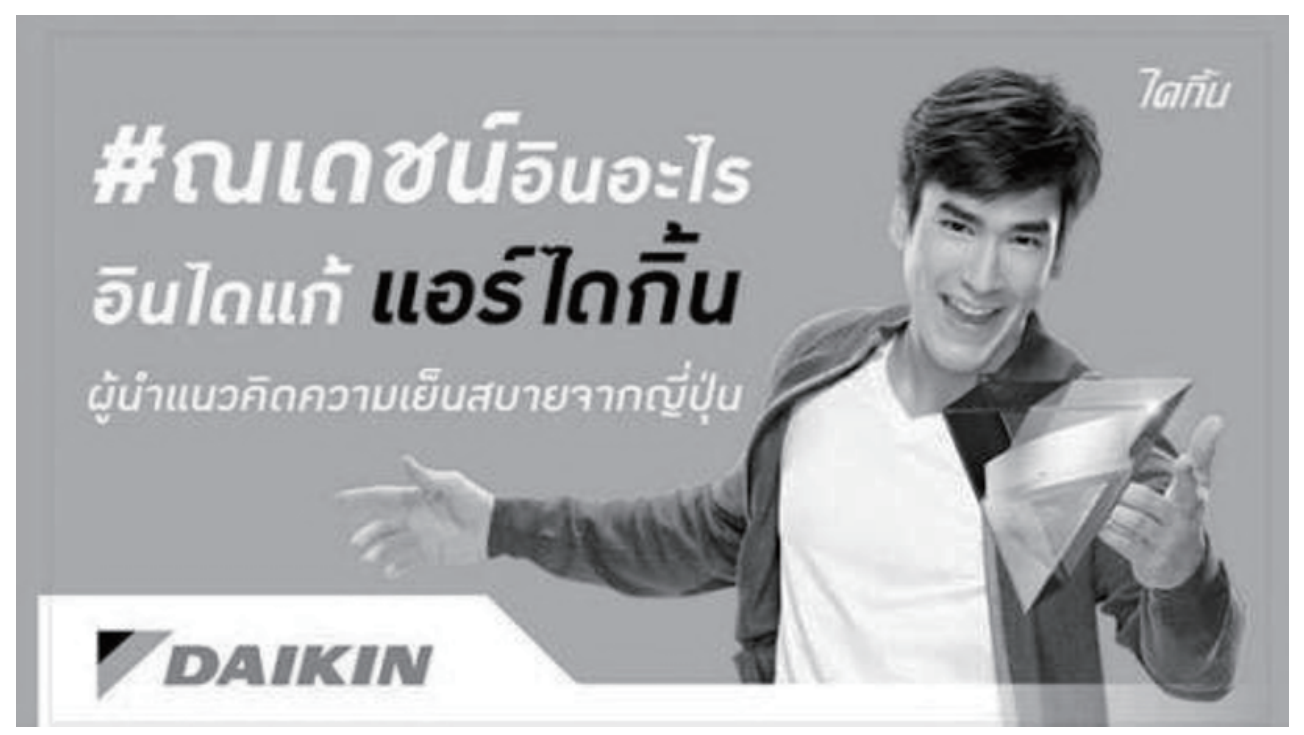

Picture 14: Daikin Air Conditioners 
A second informant, marketing consultant Nat, explained the elements in an advertisement for Daikin air conditioners (see Picture 14). It is expected that viewers first look at the presenter of the brand Nadech, currently one of the most famous actors in Thailand, because he is making eye contact with the audience. Then, the audience will read other elements such as the headline and body content from the top to bottom of the advertisement. He added that the logo cannot be bigger than the main content.

This advertisement plays with spoonerisms to render humor. The headline uses the English borrowing "in" and translates as "What is Nadech into?" followed by a nonsense sequence which is a khamphuan or play on the words "in" and "Daikin," In Dai Kae, which becomes the product name Air Daikin in dark print. This advertising also includes the borrowed word "air" to refer to an air conditioner. As with the case of "printer," there is a Thai term for air conditioner, but the Thais always use "air" in informal language. The writer might use the Thai word in a formal context, when the audience consists of educated adults. Nat explained that the reason English is used in advertising is because it is more interesting and attractive. If advertisers were to use Thai a lot, it would be perceived as boring. Nonetheless, he prefers to write English words in English not in Thai script to look more fashionable.

\section{Implications and Conclusion}

The use of the English language is ubiquitous in an English as a Foreign Language (EFL) context like Thailand. The present research explored multilingualism in advertising signage on the Skytrain. Approximately 87 percent of the data were written in either English alone or bilingual Thai-English. In addition, the $13 \%$ written exclusively in Thai script contained English borrowings.

The number and kinds of act sequences in BTS advertisements are a consequence of a number of factors including purpose, placement and intended audience. Among bilingual ads, product names and signature lines tend to be in English while the information-containing components tend to be in Thai. This is consistent with the findings in Bhatia and suggest that this may be a universal pattern, the result of globalization of products and the marketplace. The distribution of information across languages suggests that duplicating arrangements do not serve the purposes of commercial advertising. Further investigation into the kinds of information shared, how it is shared and why in bilingual fragmentary and overlapping arrangements can provide cues as to the identities and aspirations of the intended viewers, as can the kinds of information conveyed in each language in complementary arrangements. A closer look at the linguistic effects of language contact in advertisements suggests that the notion of linguistic borrowing is many faceted, including the word form, meaning, syntactic function, register, orthography and pronunciation.

From the perspective of advertising experts, English is a major strategy to attract audience and simultaneously increase a brand's value. It renders an impact as English words are usually shorter and eye-catching. Additionally, using English demonstrates a high educational level, internationalism, and advancement. 
The findings of this study also reveal that the pervasiveness of English has given rise to a nascent variety of Thai English or "Tinglish" which could become a glocal language acquiring the status as a global language but preserving a local identity (Pakir 1999), the outstanding examples of which are Indian English and Singaporean English, languages of the outer circle (Kachru 1992).

On a pragmatic level, the study of linguistic landscape can provide guidance for copy writers as well as business English instructors to examine bilingual signage and utilize it as a pedagogical tool. Students might familiarize themselves with English vocabulary in either monolingual English or bilingual EnglishThai signs. What is more, linguistic landscape of advertising is an authentic text to educate learners by business discourse analysis. This activity may allow the learners to engage in collecting the data to analyze in class.

\section{Acknowledgement}

I wish to thank Dr. Thom Huebner, a professor from San José State University for his help and guidance throughout this project. Without him, I would not have accomplished this study.

\section{References}

Backhaus, P. (2006). Multilingualism in Tokyo: A Look into the Linguistic Landscape. International Journal of Multilingualism, 3(1), pp.52-66.

Bhatia, Tej K. 1987. English in advertising: Multiple mixing and media. World Englishes 6 (1): 33-48.
Blommaert, J. (2013). Ethnography, Superdiversity and Linguistic Landscapes: Chronicles of complexity. Multilingual Maters.

BTS. (2015). BTS SkyTrain System : BTSC. [online] Available at: http://www.bts.co.th/corporate/en/02structure01.aspx [Accessed 7 Dec. 2015].

Huebner, T. (2006). Bangkok's linguistic landscapes: Environmental print, codemixing and language change.

International Journal of Multilingualism, 3(1), pp.31-51.

Huebner, T. (2009). A framework for the linguistic analysis of linguistic landscapes In: E. Shohamy and D. Gorter, ed., Linguistic Landscape: Expanding the scenery, $1 \mathrm{st}$ ed. New York: Routledge

Jaworski, A. and Thurlow, C. (2011). Semiotic landscapes. London: Continuum.

Kachreu, B. (1992). The Other Tongue: English across cultures. Champaign: University of Illinois Press.

Kasanga, L. (2012). Mapping the linguistic landscape of a commercial neighbourhood in Central Phnom Penh. Journal of Multilingual and Multicultural Development, 33(6), pp.553-567.

Lock, G. (2003). Being International, Local and Chinese: Advertisements on the Hong Kong Mass Transit Railway. Visual Communication, 2(2), pp.195-214. 
Manan, S., David, M., Dumanig, F. and Naqeebullah, K. (2014). Politics, economics and identity: mapping the linguistic landscape of Kuala Lumpur, Malaysia. International Journal of Multilingualism, 12(1), pp.31-50.

Olshtain, E. and Cohen, A. (1983). Apology: A speech act set. In N. Wolfson and E. Judd, eds., Sociolinguistics and Language Acquisition, 18-35. Rowley, MA: Newbury House.

Pakir, A. (1999). Connecting with English in the Context of Internationalisation. TESOL Quarterly, 33(1), p.103.

Schmidt, R. Shimura, A. Wang, Z. and Jeong, H-S. 1996. Suggestions to buy: Television commercials from the U.S., Japan, China, and Korea. In S. Gass and J. Neu, eds. Speech Acts Across Cultures: Challenges to Communication in a Second Language, 286-323. Berlin: Mouton de Gruyter.

Shohamy, E., Ben Rafael, E. and Barni, M. (2010). Linguistic landscape in the city. Bristol, UK: Multilingual Matters.
Spolsky, B. (2009). Prolegomena to a sociolinguistic theory of public signage. In: E. Shohamy and D. Gorter, ed., Linguistic Landscape: Expanding the scenery, 1st ed. New York: Routledge, pp.25-39.

Swales, J. M. (1990). Genre Analysis: English in Academic and Research Settings. Cambridge: Cambridge University Press.

Swales, J. M., and Feak, C. B. (2012). Academic Writing for Graduate Students: Essential tasks and skills, $r d$ 3 Edition. Ann Arbor: University of Michigan, pp. 278-402.

Toolan, M. (1988). The language of press advertising. In M. Ghadessy, ed., Registers of Written English: Situational Factors and Linguistic Features, 52-64. London: Francis Pinter. 


\section{Appendix}

\begin{tabular}{|c|cc|}
\hline Script & Lexicon & Syntax \\
\hline Thai & English & Thai \\
\hline English & English & English \\
\hline Thai & English & English \\
\hline English & English & Thai \\
\hline Thai & Thai & Thai \\
\hline$*$ English & Thai & Thai \\
\hline$*$ English & Thai & English \\
\hline$*$ Thai & Thai & \\
\hline
\end{tabular}

Table 1: Possible types of code-mixing - Thai and English (the types with asterisk were not found in the present study) 